\title{
Histological and endoscopic features of the stomachs of patients with Chagas disease in the era of Helicobacter pylori
}

\author{
Fernanda Machado Fonseca ${ }^{[1]}$, Renata Margarida Etchebehere ${ }^{[2]}$, \\ Dulciene Maria de Magalhães Queiroz ${ }^{[3]}$, Andreia Maria Camargos Rochaa ${ }^{[3]}$, \\ Iracema Saldanha Junqueira ${ }^{[4]}$, Daurin Narciso da Fonseca ${ }^{[4]}$, \\ Aline Libério Braga Rodrigues ${ }^{[1]}$, Eduardo Crema ${ }^{[5]}$ and Adriana Gonçalves de Oliveira ${ }^{[1]}$
}

[1]. Instituto de Ciências Biológicas e Naturais, Universidade Federal do Triângulo Mineiro, Uberaba, MG. [2]. Serviço de Patologia Cirúrgica, Universidade Federal do Triângulo Mineiro, Uberaba, MG. [3]. Laboratório de Pesquisa em Bacteriologia, Faculdade de Medicina, Universidade Federal de Minas Gerais, Belo Horizonte, MG. [4]. Serviço de Endoscopia, Universidade Federal do Triângulo Mineiro, Uberaba, MG. [5]. Departamento de Clínica Médica, Universidade Federal do Triângulo Mineiro, Uberaba, MG.

\begin{abstract}
Introduction: Most studies that have evaluated the stomachs of patients with Chagas disease were performed before the discovery of Helicobacter pylori and used no control groups. This study compared the gastric features of chagasic and non-chagasic patients and assessed whether gastritis could be associated with Chagas disease. Methods: Gastric biopsy samples were taken from patients who underwent endoscopy for histological analysis according to the Updated Sydney System. H. pylori infection was assessed by histology, $16 \mathrm{~S}$ ribosomal ribonucleic acid (rRNA) polymerase chain reaction (PCR), serology and the ${ }^{13} \mathrm{C}$-urea breath test. Patients were considered $H$. pylori-negative when all of these diagnostic tests were negative. Clinical and sociodemographic data were obtained by reviewing medical records and using a questionnaire. Results: The prevalence of $H$. pylori infection ( $70.3 \%$ versus $71.7 \%$ ) and chronic gastritis $(92.2 \%$ versus $85 \%)$ was similar in the chagasic and non-chagasic groups, respectively; such as peptic ulcer, atrophy and intestinal metaplasia. Gastritis was associated with H. pylori infection independent of Chagas disease in a log-binomial regression model. However, the chagasic H. pylori-negative patients showed a significantly higher grade of mononuclear (in the corpus) and polymorphonuclear (PMN) (in the antrum) cell infiltration. Additionally, the patients with the digestive form of Chagas disease showed a significantly lower prevalence of corpus atrophy than those with other clinical forms. Conclusions: The prevalence of H. pylori infection and of gastric histological and endoscopic features was similar among the chagasic and non-chagasic patients. Additionally, this is the first controlled study to demonstrate that $H$. pylori is the major cause of gastritis in patients with Chagas disease.
\end{abstract}

Keywords: Helicobacter pylori infection. Chagas disease. Gastritis.

\section{INTRODUCTION}

Chagas disease, which is a zoonosis caused by the protozoan Trypanosoma cruzi, affects approximately 8 million people in Latin America ${ }^{1}$. In endemic areas, T. cruzi is commonly transmitted to humans through triatomine vectors; however, in non-endemic areas where the vector is lacking, $T$. cruzi can be transmitted horizontally through blood transfusions or through organ and tissue transplantation or transmitted vertically from

\footnotetext{
Address to: Dra. Adriana Gonçalves de Oliveira. ICBN/UFTM. Praça Manoel Terra 330, 38015-050 Uberaba, MG, Brasil.

Phone: 55343318 5480; Fax: 553433185462

e-mail: agoliveira@dcb.uftm.edu.br

Received 4 August 2014

Accepted 27 November 2014
}

infected mothers to their offspring. Currently, thousands of people with Chagas disease are estimated to live in the USA, Europe and Asia due to the migration of infected individuals from endemic areas ${ }^{2,3}$.

The acute phase of Chagas disease is usually asymptomatic, and this disease progresses to a chronic phase, called the indeterminate form, which generally starts with a long period characterized by the absence of symptoms ${ }^{4}$. Several years after the initial infection, approximately $20-30 \%$ of infected people will develop lesions in the heart and gastrointestinal tract that are characteristic of the other clinical forms of Chagas disease ${ }^{1}$. The primary clinical manifestations of the chronic cardiac form of Chagas disease are heart failure, cardiac arrhythmia, and thromboembolism ${ }^{4}$. In the digestive form of this disease, the clinical manifestations are due the destruction of the intramural plexuses, primarily the myenteric plexus, leading to the incoordination of peristalsis and sphincter 
achalasia of the esophagus and resulting in megaesophagus and megacolon ${ }^{5,6}$. Some patients can simultaneously develop lesions in the heart and digestive tract, which are characteristic of the cardiodigestive form of chronic Chagas disease.

Previously, the chronic gastritis commonly observed in chagasic patients primarily with the digestive form of Chagas disease was attributed to biliary duodenal-gastric reflux, as well as gastric hypomotility and hypochlorhydria caused by enteric nervous system injury due to chronic $T$. cruzi infection ${ }^{7-11}$. However, these studies were performed before the recognition that infection with the bacterium Helicobacter pylori is the main cause of chronic gastritis throughout the world and plays an important role in peptic ulcers, gastric carcinoma and mucosaassociated lymphoid tissue (MALT) lymphoma ${ }^{12}$.

After the discovery of $H$. pylori, two uncontrolled studies that evaluated a small group of patients with the digestive ${ }^{13}$ and indeterminate ${ }^{14}$ forms of Chagas disease reported a high prevalence rate of both gastritis and H. pylori infection $(\sim 95 \%)$ in these patients using histological diagnosis. Later, Pinazo et al. ${ }^{15}$ detected a high prevalence of $H$. pylori infection, which was diagnosed using the urea breath test, among Latin American immigrants living in Barcelona that had the digestive form of Chagas disease. Recently, two controlled studies ${ }^{16,17}$ demonstrated a significantly higher seroprevalence of $H$. pylori infection among chagasic patients independent of the clinical form of the disease; however, the gastric mucosa of the patients was not evaluated in either study or in the study by Pinazo et al. ${ }^{15}$.

Therefore, the aim of this study was to compare the prevalence of $H$. pylori infection and the gastric histological and endoscopic features of chagasic and non-chagasic patients and of chagasic patients with the digestive form of Chagas disease and those with other clinical forms because data regarding alterations in the gastric mucosa of chagasic patients, especially after the discovery of $H$. pylori, are lacking. In addition, whether gastritis could be associated with Chagas disease was assessed.

\section{METHODS}

\section{Patients and clinical samples}

From July 2007 to November 2011, gastric biopsy specimens were obtained from consecutive chagasic (cases) and non-chagasic (controls) outpatients who underwent upper gastrointestinal endoscopy at the Endoscopic Service of Universidade Federal do Triângulo Mineiro (UFTM) for an evaluation of dyspeptic symptoms or as a follow-up for chronic Chagas disease. These patients were from the same geographical region and lived in a rural or urban area of Uberaba and other nearby cities west of the State of Minas Gerais, Brazil in a region called Triângulo Mineiro, which was previously considered an endemic area for Chagas disease. During endoscopy, the biopsy specimens were obtained from the antrum and corpus of the stomach of each patient for histological and molecular analysis. The exclusion criteria were previous therapy for the eradication of $H$. pylori infection, pregnancy, the presence of coagulation disorders, complications such as perforation or gastric bleeding, anatomical impediment to endoscopy, esophageal varices, and concomitant severe illness. Additionally, $5 \mathrm{~mL}$ of blood was collected from each patient for the serological diagnosis of Chagas disease and for the detection of anti-H. pylori immunoglobulin $\mathrm{G}(\mathrm{IgG})$.

\section{Ulcers and esophagitis}

Ulcers were diagnosed from endoscopic findings and further stratified according to the location into gastric or duodenal ulcers ${ }^{18}$. Esophagitis was defined as the presence of one or more mucosal breaks and was graded according to the Los Angeles classification system ${ }^{19}$.

\section{Chagas disease diagnosis}

Enzyme-linked immunosorbent assay (ELISA) (Chagatest ELISA, Wiener Laboratories, Rosario, Argentina), hemagglutination (HA) (Chagatest HAI, Wiener Laboratories, Rosario, Argentina) and immunofluorescence (Immuno-Con Chagas, WAMA Diagnostica, São Carlos, Brazil) tests were performed according to the manufacturers' instructions. The chagasic patients showed positive reactions to at least two serological tests, and the non-chagasic patients displayed negative reactions to all three tests used. The patients with only one positive test were excluded. The chagasic patients were classified according to the clinical form of the disease (i.e., indeterminate, digestive, cardiac or cardiodigestive) based on the results of a conventional electrocardiogram and of a contrast X-ray of the esophagus and colon.

\section{Histological analysis}

The endoscopic biopsy samples from the gastric mucosa of the antrum and corpus were fixed overnight in buffered formalin, and embedded in paraffin. Then, each paraffin block was sliced to 4- $\mu \mathrm{m}$ thickness and stained with hematoxylin and eosin for histological examination.

All of the samples were examined by the same experienced pathologist who was blinded to the patients' clinical information. The presence of mononuclear cell infiltration indicated chronic gastritis, and polymorphonuclear (PMN) cell infiltration signified gastritis activity. The degrees of gastric mucosal inflammation (mononuclear cells) and of gastritis activity (PMN cells) were assessed in accordance with the Updated Sydney System and were classified using the following four grades: 0 : none; 1 : mild; 2 : moderate; and 3 : severe $^{20}$. The gastritis location was classified according to the presence of mononuclear cells in the antrum, corpus or both. Glandular atrophy and intestinal metaplasia were classified as absent or present.

Helicobacter pylori infection was diagnosed histologically by direct light microscopic observation of the organism using Warthin-Starry staining. The infection was considered negative if the bacterium was absent from all of the biopsy sites and positive if the bacterium was present in at least one of the biopsy sites. The location of $H$. pylori was classified according to the presence of bacteria in the antrum, corpus or both.

\section{Helicobacter pylori status}

The histological analysis, urea breath test, $16 \mathrm{~S}$ rRNA PCR, and anti-H. pylori $\operatorname{IgG}$ (serology) detection were performed to determine the $H$. pylori status. The patients for whom two of 
the tests were positive were classified as $H$. pylori-positive, and the patients for whom all of the tests were negative were considered $H$. pylori-negative. The patients using a proton pump inhibitor (PPI) and/or antibiotics with gastric histological alterations were considered $H$. pylori-positive even if they were positive by the serological testing alone.

\section{${ }^{13} \mathrm{C}$-Urea breath test}

The urea breath test (UBT) was performed after $6 \mathrm{~h}$ of fasting. A first basal breath sample was collected, and then, an oral dose of $75 \mathrm{mg}$ of ${ }^{13} \mathrm{C}$-urea dissolved in $200 \mathrm{~mL}$ of orange juice was administered. An additional breath sample was collected after $30 \mathrm{~min}$. The breath samples were analyzed using an isotope-selective non-dispersive infrared spectrometer (NDIRIS; Wagner Analytical Systems, Bremen, Germany). A change in the delta over baseline (DOB) value of $>4 \%$ was considered $H$. pylori-positive ${ }^{21}$.

\section{S RNA gene detection}

Antrum or corpus tissue deoxyribonucleic acid (DNA) was extracted using a commercial kit (QIAamp DNA Mini Kit; Qiagen, Hilden, Germany), according to the manufacturer's instructions with minor modifications. The presence of $H$. pylori DNA was detected by the amplification of the 16S rRNA gene by PCR using specific primers described previously by Riley et al. ${ }^{22}$. The amplification products were visualized by $1.5 \%$ agarose gel electrophoresis. The gels were stained with ethidium bromide and observed under UV light.

\section{Anti-Helicobacter pylori IgG detection}

IgG antibodies specific to $H$. pylori were detected using a commercial ELISA kit (Pyloriset EIA-GIII; Orion Diagnostica, Espoo, Finland). The antigen employed in this kit is a cell surface protein of $H$. pylori strain NCTC 11637 . The assay was performed according to the manufacturer's instructions. The concentrations of the IgG antibodies in the serum samples were determined by interpolation from a standard curve constructed by plotting the absorbance values obtained for each of the 4 calibrator sera samples, which are provided by the manufacturer, against the corresponding anti-H. pylori concentrations in $\mathrm{U} / \mathrm{mL}$.

\section{Statistical analysis}

The data were analyzed using the Statistical Package for the Social Sciences (SPSS) software (version 16.0; SPSS Inc., Chicago, IL, USA). The association of variables such as H. pylori infection, chronic gastritis, active gastritis, atrophy, metaplasia, gastric ulcers, and esophagitis with Chagas disease and with the digestive clinical form was assessed by a prevalence ratio (PR), chi-square and Fisher's exact test as appropriate. An adjusted analysis for age and sex (confounding factors) was also performed. In addition, a model of log-binomial regression for potentially confounding factors, such as gender, mean age, alcohol consumption, and PPI and non-steroidal antiinflammatory drug (NSAID) usage, was constructed to evaluate the association between chronic gastritis and Chagas disease or H. pylori infection. The prevalence ratios (PRs) and the $95 \%$ confidence intervals (CIs) were determined. The significance level was set at 5\%. The intensity (mononuclear cell) and activity (polymorphonuclear cell) of gastritis were compared by the Mann-Whitney U test.

\section{Ethical considerations}

This study was approved by the Ethics Committee of the Universidade Federal do Triângulo Mineiro (UFTM), Uberaba, Minas Gerais (MG), Brazil and was conducted in accordance with the Declaration of Helsinki. All patients provided their signed written informed consent forms and answered a questionnaire to obtain socio-demographic data. The clinical information was obtained by reviewing the patients' medical records.

\section{RESULTS}

In total, 184 patients were included in the study. Of these patients, 64 (34.8\%) were chagasic (32 male and 32 female; mean age $62.5 \pm 9.4$ years $)$ and $120(65.2 \%)$ were non-chagasic (38 male and 82 female; mean age $47.6 \pm 14.3$ years). The prevalence rates of $H$. pylori infection and the gastric features of chagasic and non-chagasic patients are summarized in Table 1. No significant differences were observed between the chagasic and non-chagasic groups regarding $H$. pylori-positive status, chronic gastritis, chronic active gastritis, atrophy, intestinal metaplasia, esophagitis, and gastric ulcers. Although duodenal ulcers were observed only among the non-chagasic patients $(p=0.01)$, the difference was not significant after adjusting for age and $\operatorname{sex}(p=1.0)$. All of the chagasic patients with gastric ulcers and the majority of the non-chagasic patients with gastric ulcers ( 8 of $10 ; 80 \%)$ and duodenal ulcers (10 of $11 ; 90.9 \%)$ were $H$. pylori-positive. Higher rates of $H$. pylori positivity among the chagasic and non-chagasic patients were detected by serology (67.2\% and $75.8 \%$, respectively) compared with detection by $16 \mathrm{~S}$ rRNA PCR $(62.5 \%$ and $61.7 \%$, respectively), histology (64.1\% and $57.5 \%$, respectively), and the UBT $(52.7 \%$ and $62.1 \%$, respectively). The bacterium was in both the antrum and corpus gastric regions in $71.1 \%$ of the chagasic and $57 \%$ of the non-chagasic $H$. pylori-positive patients, similar to the results for the location of gastritis (57.8\% and $51.2 \%$, respectively).

Chronic gastritis was associated with $H$. pylori infection $(\mathrm{p}<0.01)$ independent of Chagas disease and of the other covariables that were evaluated (Table 2). However, we found $H$. pylori-negative patients with gastritis in both the chagasic and non-chagasic groups, as shown in Table 3. Six (31.6\%) of the 19 chagasic and one of the $34(2.9 \%)$ non-chagasic $H$. pylori-negative patients showed PMN cell infiltration (chronic active gastritis) in the antrum or corpus, whereas higher numbers of the $H$. pylori-negative chagasic (14 of $19 ; 73.7 \%$ ) and the non-chagasic (17 of $34 ; 50 \%)$ patients showed mononuclear cell infiltration (chronic gastritis). However, no $H$. pylori-negative patients who presented PMN cell infiltration were graded as moderate or severe, and none that presented mononuclear cell infiltration was graded as severe. Notably, the group of chagasic $H$. pylori-negative patients exhibited higher grades of mononuclear $(\mathrm{p}<0.01)$ and 
TABLE 1 - A comparison of the prevalence of Helicobacter pylori infection and gastric histological and endoscopic features among chagasic and non-chagasic patients.

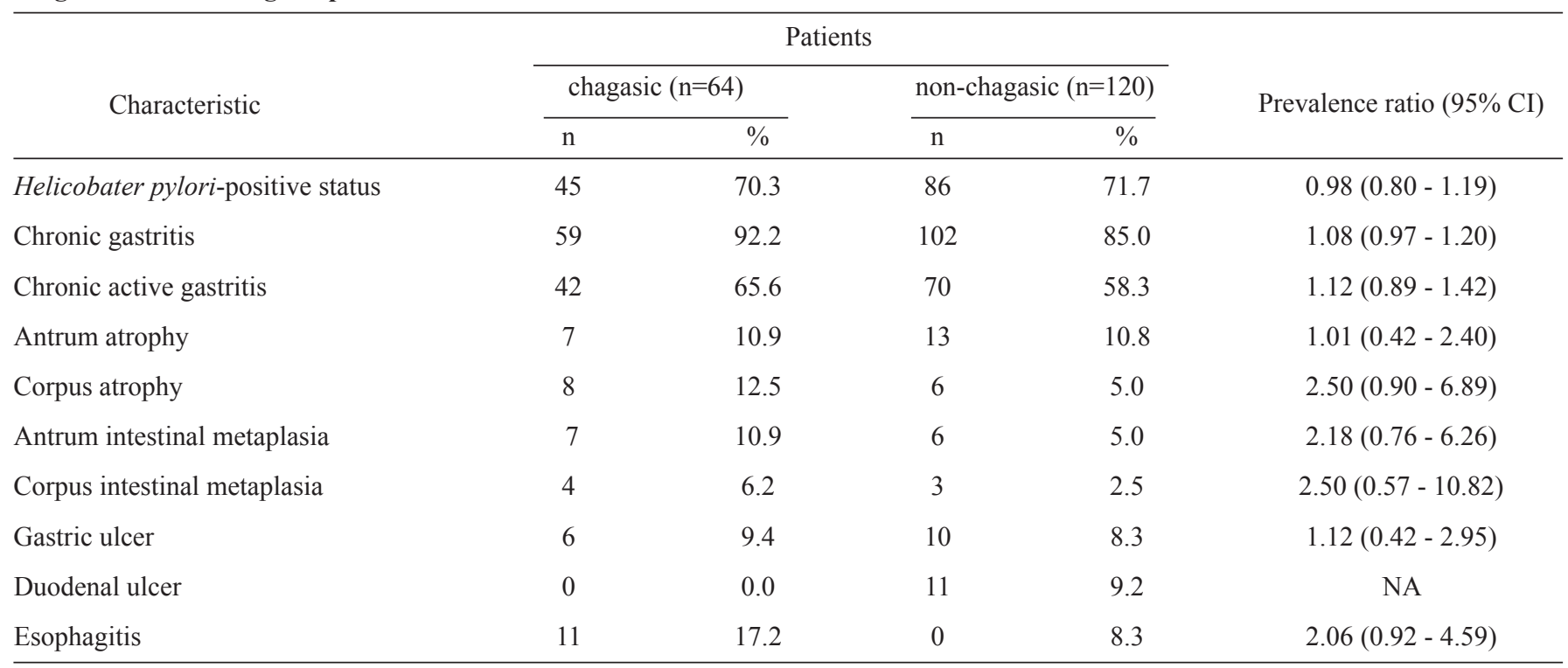

NA: not applicable; $\mathbf{9 5} \%$ CI: $95 \%$ confidence interval.

TABLE 2 - Variables associated with chronic gastritis in a log-binomial regression.

\begin{tabular}{lcccc}
\hline \multirow{2}{*}{ Variables } & \multicolumn{2}{c}{ Initial model } & \multicolumn{2}{c}{ Final model } \\
\cline { 2 - 3 } Chagas disease positive & 0.27 & PR $(95 \% \mathrm{CI})$ & & $\mathrm{p}$ \\
Gender (female) & 0.13 & $0.48(0.18-1.25)$ & & $<0.01$ \\
H. pylori-positive status & $<0.01$ & $52.96(7.59-369.29)$ & $54.38(7.52-393.23)$ \\
NSAID use & 0.84 & $0.93(0.48-1.80)$ & & \\
PPI use & 0.49 & $1.27(0.63-2.55)$ & & \\
\end{tabular}

The mean age of the patients with chronic gastritis was $52.5 \pm 14.7$ years $(\mathrm{p}=0.57)$. PR: prevalence ratio; 95\% CI: $95 \%$ confidence interval; H.: Helicobacter; NSAID: non-steroidal anti-inflammatory drug; PPI: proton pump inhibitor.

$\operatorname{PMN}(\mathrm{p}=0.03)$ cell infiltration in the corpus and antrum regions, respectively, compared with the non-chagasic group. Four (29\%) of 14 chagasic patients with $H$. pylori-negative gastritis showed corpus-predominant immune cell infiltration $(\mathrm{p}=0.06)$. No significant difference was observed between the groups of chagasic and non-chagasic $H$. pylori-positive patients regarding the grade of gastric cell infiltration in both the antral and corpus mucosa. However, the chagasic and non-chagasic H. pyloripositive patients showed higher grades of mononuclear and PMN cell infiltration in the antrum and corpus regions compared with $H$. pylori-negative patients $(\mathrm{p}<0.01)$.

Among the 64 patients with Chagas disease, 40 (62.5\%) had the digestive form of the disease, $13(20.3 \%)$ had the cardiodigestive form, $8(12.5 \%)$ had the indeterminate form, and three $(4.7 \%)$ had the cardiac form of the disease. The patients with the digestive form had megaesophagus $(n=33)$, megacolon $(n=2)$ or both alterations $(n=5)$. The mean ages of the patients with the digestive form and of the patients with the other clinical forms of Chagas disease were $62.1 \pm 9.7$ years and $63.1 \pm 9.0$ years, respectively $(\mathrm{p}=0.60)$. Twenty-four $(60 \%)$ patients with the digestive form and $8(33.3 \%)$ with other clinical forms were male $(p=0.04)$. Seventeen $(42.5 \%)$ chagasic patients with the digestive form and $7(29.2 \%)$ with other clinical forms $(p=0.26)$ were using PPIs. A comparison of the H. pylori prevalence and gastric features of the subgroups of the chagasic patients with the digestive form $(n=40)$ and of the patients with other clinical forms $(n=24)$ is shown in Table 4. No significant differences were observed between the chagasic patient subgroups regarding H. pylori status, chronic gastritis, chronic active gastritis, gastric ulcers and esophagitis. Intestinal metaplasia and atrophy were detected in the antrum region in a higher percentage of the patients with the digestive form of Chagas disease than among those patients with other clinical forms. In contrast, intestinal 
TABLE 3 - The grade of mononuclear and polymorphonuclear cell infiltration in the antrum and corpus gastric regions of the chagasic $(n=64)$ and non-chagasic $(n=120)$ patients according to the Helicobacter pylori status.

\begin{tabular}{|c|c|c|c|c|c|c|c|c|c|c|c|c|c|c|c|c|}
\hline \multirow{3}{*}{ Grade of cell infiltration } & \multicolumn{8}{|c|}{ Helicobacter pylori-positive patients } & \multicolumn{8}{|c|}{ Helicobacter pylori-negative patients } \\
\hline & \multicolumn{2}{|c|}{ chagasic } & \multicolumn{2}{|c|}{ non-chagasic } & \multicolumn{2}{|c|}{ chagasic } & \multicolumn{2}{|c|}{ non-chagasic } & \multicolumn{2}{|c|}{ chagasic } & \multicolumn{2}{|c|}{ non-chagasic } & \multicolumn{2}{|c|}{ chagasic } & \multicolumn{2}{|c|}{ non-chagasic } \\
\hline & $\mathrm{n}$ & $\%$ & $\mathrm{n}$ & $\%$ & $\mathrm{n}$ & $\%$ & $\mathrm{n}$ & $\%$ & $\mathrm{n}$ & $\%$ & $\mathrm{n}$ & $\%$ & $\mathrm{n}$ & $\%$ & $\mathrm{n}$ & $\%$ \\
\hline \multicolumn{17}{|l|}{ Mononuclear } \\
\hline 1 & 15 & 23.4 & 31 & 25.8 & 22 & 34.4 & 34 & 28.3 & 6 & 9.4 & 17 & 14.2 & 9 & 14.1 & 7 & 5.8 \\
\hline 2 & 25 & 39.1 & 50 & 41.7 & 14 & 21.9 & 32 & 26.4 & 5 & 7.8 & 0 & 0.0 & 2 & 3.1 & 0 & 0.0 \\
\hline 3 & 5 & 7.8 & 3 & 2.5 & 7 & 10.9 & 6 & 5.0 & 0 & 0.0 & 0 & 0.0 & 0 & 0.0 & 0 & 0.0 \\
\hline \multicolumn{17}{|l|}{ Polymorphonuclear } \\
\hline 3 & 4 & 6.3 & 8 & 6.7 & 5 & 7.8 & 3 & 2.5 & 0 & 0.0 & 0 & 0.0 & 0 & 0.0 & 0 & 0.0 \\
\hline
\end{tabular}

$\mathbf{a} \mathrm{p}<0.05$ for the chagasic versus non-chagasic patients for PMN cell infiltration; $\mathbf{b} p<0.05$ for the chagasic versus non-chagasic patients for mononuclear cell infiltration. PMN: polymorphonuclear.

metaplasia and atrophy of the corpus mucosa were more frequent in the chagasic patients with other clinical forms than among those patients with the digestive form; however, a significant difference was observed only for atrophy even after adjusting for gender $(\mathrm{p}=0.02)$.

\section{DISCUSSION}

Approximately half of the world's population is estimated to be infected with $H$. pylori, which is a Gram-negative bacterium that is now considered the most common cause of gastritis. All H. pylori-infected individuals develop chronic gastritis due a local immune response to the bacterium; however, most infected individuals remain asymptomatic. Long-term gastric inflammation leads to more serious outcomes, such as peptic ulcer disease, gastric atrophy (a precursor of gastric carcinoma) and mucosaassociated lymphoid tissue lymphoma, in a small percentage of infected individuals. We found a high prevalence of gastritis and H. pylori infection in both groups of chagasic and non-chagasic patients in the present study. Although two previous studies have reported similar findings for a small group of chagasic patients ${ }^{13,14}$, this is the first controlled study to demonstrate that H. pylori is the major cause of gastritis in patients with Chagas disease.

Moreover, we found some chagasic and non-chagasic patients with gastritis who were not infected with $H$. pylori. This phenomenon of chronic active gastritis with no detectable H. pylori seems to be increasingly common in the Western world, and some possible explanations for this phenomenon include antibiotic therapy for the treatment of other infections, the widespread use of PPIs, and inadequate sampling or suboptimal staining techniques as suggested previously ${ }^{23-25}$. However, we used multiple diagnostic tests in the present study to avoid false H. pylori-negative results because no single test is considered the gold standard for the diagnosis of $H$. pylori infection. The tests in the present study included a commercial serological test that has high sensitivity and specificity ${ }^{26}$ and that is not influenced by a temporary or recent decrease in the bacterial load caused by PPI usage and by nonspecific antibiotic therapy. Taken together, we believe that the chance of having patients with false $H$. pylori-negative gastritis in the study population is low. Therefore, other causes of gastritis should be considered in patients with $H$. pylori-negative gastritis, especially among those patients with Chagas disease because, interestingly, the intensity (in the corpus mucosa) and the activity (in the antral mucosa) of gastritis were significantly higher in this group of patients than in the non-chagasic group, as demonstrated in Table 3. Based on these findings, one may speculate that factors inherent to T. cruzi infection could induce the development of gastritis in $H$. pylori-negative patients; this hypothesis merits further investigation.

Other causes of gastritis that may mimic H. pylori infection include reactive (or chemical) gastritis with focal activity, autoimmune gastritis, lymphocytic gastritis, and other infections ${ }^{20}$. Notably, approximately $29 \%$ of chagasic patients with $H$. pylori-negative gastritis showed corpus-predominant immune cell infiltration, which is a common characteristic of autoimmune gastritis. In contrast, no control patients with H. pylori-negative gastritis presented immune cell infiltration predominantly in the corpus mucosa. Bile-associated chemical 
TABLE 4 - A comparison of the prevalence of Helicobacter pylori infection and gastric histological and endoscopic features among the chagasic patients with digestive $(n=40)$ and other clinical forms $(n=24)$ of the disease.

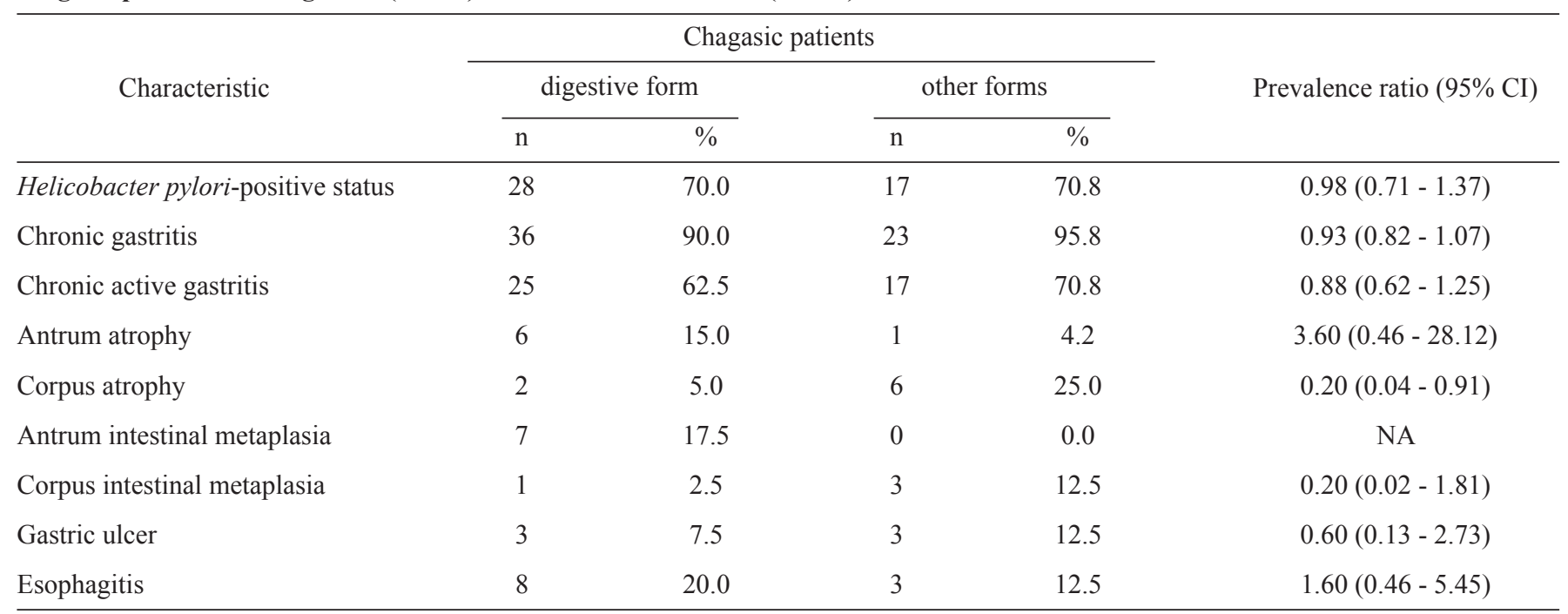

NA: not applicable; $\mathbf{9 5 \%}$ CI: $95 \%$ confidence interval.

gastritis may be another cause of gastritis, especially among chagasic patients, because earlier studies demonstrated that duodenogastric reflux is common in chagasic patients with megaesophagus ${ }^{11}$.

Chronic H. pylori infection exerts profound and diverse effects on gastric acid secretion that depend on the gastritis degree and location and that are related to the disease outcome. In subjects with predominantly antral gastritis, $H$. pylori increases acid secretion, predisposing patients to duodenal ulcers, whereas in other patients with predominantly corpus gastritis or pangastritis, acid secretion is impaired, resulting in gastric atrophy, and these subjects have an increased risk of gastric cancer ${ }^{27}$. In Chagas disease, although the most significant digestive manifestation is the development of megaesophagus and/or megacolon, a partial denervation of the stomach at the level of the intramural plexuses has been reported, inducing several gastric motor and secretory disturbances, including delayed gastric emptying of solids, hypergastrinemia and reduced gastric acid secretion ${ }^{6,11,28}$. However, the gastric physiological changes and the effects on the clinical outcome that could be caused by long-term co-infection with $H$. pylori and T. cruzi are unknown.

Before the discovery of $H$. pylori, hypochlorhydria in patients with Chagas disease was believed to be a protective factor for duodenal ulcers, and hypomotility along with gastric stasis was thought to cause an increase of gastric ulcers. In an earlier study, Ceneviva et al. ${ }^{29}$ evaluated patients with peptic ulcers undergoing surgery and reported a higher prevalence of gastric ulcers than duodenal ulcers among those patients with Chagas disease. In the present study, the prevalence of gastric ulcers was also higher than duodenal ulcers among the chagasic patients; however, no significant difference was observed compared with the control group. In contrast, two uncontrolled studies of patients with megaesophagus ${ }^{11}$ and with the indeterminate ${ }^{14}$ clinical form of Chagas disease showed a similar prevalence of gastric ulcers and duodenal ulcers. A critical comparison of the findings of all of these studies is hampered because the study designs and the clinical forms of the evaluated chagasic patients are different. Nevertheless, all chagasic patients with gastric ulcers in the present study were $H$. pylori-positive, suggesting that this gastric disease is associated with $H$. pylori infection and not with Chagas disease.

Overall, the prevalence of gastric atrophy and intestinal metaplasia in the antrum and corpus was similar between the chagasic and non-chagasic patients. However, the reasons why patients with other clinical forms of Chagas disease showed a significantly higher prevalence of corpus-predominant atrophy than those patients with the digestive clinical form are unknown. Nonetheless, we believe that this finding is not associated with PPI usage because the percentages of the chagasic patients with the digestive form and with other clinical forms taking this medication were similar. Two other studies have also assessed the gastric histological features of chagasic patients, although only the antral mucosa was examined. Barbosa et al. ${ }^{13}$ reported antrum atrophy in $47 \%$ of patients with the digestive form, which is a higher prevalence than that found in our present study $(15 \%)$. In contrast, Oliveira et al. ${ }^{14}$ did not find atrophy or intestinal metaplasia among patients with the indeterminate form of Chagas disease.

The high prevalence of co-infection with $T$. cruzi and H. pylori in our study (approximately $70 \%$ ) and in other studies is not surprising because the transmission of both of these pathogens is associated with poor socioeconomic conditions ${ }^{13-17}$. Moreover, in Brazil, which is considered a developing country, the overall prevalence of $H$. pylori is high and varies from $55 \%$ to $87 \%$ according to the geographical region ${ }^{30,31}$. Notably, no significant differences in the prevalence of infection with H. pylori among the clinical forms of Chagas disease were observed in the present study or in other previous studies ${ }^{16,17}$. 
This finding indicates that patients with the digestive form are not at high risk for $H$. pylori infection, although these patients have hypochlorhydria ${ }^{7,8,10}$, which a condition that can favor gastric colonization by $H$. pylori ${ }^{32,33}$.

In conclusion, the prevalence of $H$. pylori infection and gastric histological and endoscopic features was similar among the chagasic and non-chagasic patients. Additionally, our findings indicate $H$. pylori infection as the major cause of chronic gastritis in patients with Chagas disease, although the impact of Chagas disease on gastritis cannot be excluded, especially in $H$. pylori-negative patients. Furthermore, considering the high prevalence of $H$. pylori among chagasic patients irrespective of the clinical form of the disease, we believe that the investigation and eradication of $H$. pylori infection may result in an improvement of non-specific upper gastrointestinal symptoms among patients with Chagas disease, in addition to preventing the development of more severe gastric diseases associated with $H$. pylori.

\section{ACKNOWLEDGMENTS}

We thank Dr. Aluízio Prata (in memoriam) for encouraging us to perform this study and Dr. Marcus Vinícius Castro for the statistical support.

\section{CONFLICT OF INTEREST}

The authors declare that there is no conflict of interest.

\section{FINANCIAL SUPPORT}

This work was supported by grants from the Fundação de Amparo à Pesquisa do Estado de Minas Gerais (FAPEMIG) and from the Conselho Nacional de Desenvolvimento Cientifico e Tecnológico (CNPq), Brazil.

\section{REFERENCES}

1. World Health Organization (WHO). Technical report of the TDR disease reference group on Chagas disease, human African trypanosomiases and leishmaniasis. Research priorities for Chagas disease, human African trypanosomiasis and leishmaniasis. Technical report series. WHO; 2012. p. 975. [Cited 2013 December 18]. Available at: www.who.int/iris/.../1/WHO_TRS_975_eng.pdf/.

2. Gascon J, Bern C, Pinazo MJ. Chagas disease in Spain, the United States and other non-endemic countries. Acta Trop 2010; 115:22-27.

3. Tanowitz HB, Weiss LM, Montgomery SP. Chagas disease has now gone global. PloS Negl Trop Dis 2011; 5:1-2.

4. Prata A. Clinical and epidemiological aspects of Chagas Disease. Lancet Infect Dis 2001; 1:92-100.

5. Costa RB, Alcântara FG. Chronic Chagas' gastropathy. Rev Bras Med 1965; 22:667-671

6. Oliveira RB, Troncon LEA, Dantas RO, Menghelli UG. Gastrointestinal manifestations of Chagas disease. Am J Gastroenterol 1998; 93:884-889.
7. Oliveira CACP. Gastric acidity in Chagas' disease patients: study using the maximal histalog test. Rev Assoc Med Bras 1972; 18:145-150.

8. Padovan W, Godoy RA, Meneghelli UG, Dantas RO, Oliveira RB, Troncon LE. Acid and pepsin secretion in chronic Chagas' disease patients in response to graded doses of pentagastrin and pentagastrin plus bethanecol. Digestion 1982; 23:48-56.

9. Rezende JM. The digestive tract in Chagas' disease. Mem Inst Osw Cruz 1984; 79:97-106.

10. Troncon LEA, Oliveira RB, Meneghelli UG, Dantas RO, Godoy RA. Fasting and food-stimulated plasma gastrin levels in chronic Chagas' disease. Digestion 1984; 29:171-176.

11. Rezende JM, Rosa H, Vaz MGM, Andrade-Sá N, Porto JD, Neves Neto J, et al. Endoscopy in megaesophagus: prospective study of 600 cases. Arq Gastroenterol 1985; 22:53-62.

12. Brown LM. Helicobacter pylori: epidemiology and routes of transmission. Epidemiol Rev 2000; 22:283-297.

13. Barbosa AJ, Queiroz DM, Nogueira AM, Roquette Reis MJ, Mendes EN, Rocha GA, et al. Chronic gastritis and Helicobacter pylori in digestive form of Chagas' disease. Rev Inst Med Trop São Paulo 1993; 35:117-121.

14. Oliveira LCM, Buso AG, Siqueira Filho L, Moraes F, Oliveira HA, Oliveira RM, et al. Peptic disease and Helicobacter pylori are highly prevalent in patients with the indeterminate form of Chagas' disease: report of 21 cases. Rev Inst Med Trop São Paulo 1997; 39: $209-212$.

15. Pinazo MJ, Elizalde JI, Posada EJ, Gascón J. Co-infection with two emergent old pathogens: Trypanosoma cruzi and Helicobacter pylori. Enferm Infecc Microbiol Clin 2010; 28:751-752.

16. Nascimento RS, Valente SR, Oliveira LCM. Seroprevalence of Helicobacter pylori infection in chronic chagasic patients, and in the rural and urban population from Uberlândia, Minas Gerais, Brazil. Rev Inst Med Trop São Paulo 2002; 44:251-254.

17. Fonseca FM, Queiroz DMM, Rocha AMC, Prata A, Crema E, Rodrigues Junior V, et al. Seroprevalence of Helicobacter pylori infection in chagasic and non-chagasic patients from the same geographical region of Brazil. Rev Soc Bras Med Trop 2012; 45:194-198.

18. Tytgat GN. The Sydney System: endoscopic division. Endoscopic appearances in gastritis/duodenitis. J Gastroenterol Hepatol 1991; 6:223-234.

19. Armstrong D, Bennett JR, Blum AL, Dent J, De Dombal FT, Galmiche JP, et al. Endoscopic assessment of esophagits: a progress report on observer agreement. Gastroenterol 1996; 111:85-92.

20. Dixon MF, Genta RM, Yardley JH, Correa P. Classification and grading of gastritis. The updated Sydney System. International Workshop on the Histopathology of Gastritis, Houston 1994. Am J Surg Pathol 1996; 20:1161-1181.

21. Cardinali LCC, Rocha GA, Rocha AM, Moura SB, Figueiredo TS, Esteves AM, et al. Evaluation of ${ }^{13} \mathrm{C}$-urea breath test and Helicobacter pylori stool antigen test for diagnosis of $H$. pylori infection in children from a developing country. J Clin Microbiol 2003; 41:333-335.

22. Riley LK, Franklin CL, Hook Jr RR, Besch-Williford C. Identification of murine Helicobacters by PCR and restriction enzyme analyses. J Clin Microbiol 1996; 34:942-946.

23. Genta RM, Schuler CM, Lash RH. Helicobacter pylori-negative chronic active gastritis: a new entity or the result of widespread acid inhibition? Gastroenterol 2008; 134:A-125. 
24. Genta RM, Lash RH. Helicobacter pylori-negative gastritis: seek, yet ye shall not always find. Am J Surg Pathol 2010; 34:e-25-34.

25. Nordenstedt H, Graham DY, Kramer JR, Rugge M, Verstovsek G, Fitzgerald S, et al. Helicobacter pylori-negative gastritis: prevalence and risk factors. Am J Gastroenterol 2013; 108:65-71.

26. Granberg C, Mansikka A, Lehtonen OP, Kujari H, Grönfors R, Nurmi H, et al. Diagnosis of Helicobacter pylori infection by using pyloriset EIA-G and EIA-A for detection of serum immunoglobulin G (IgG) and IgA antibodies. J Clin Microbiol 1993; 31:1450-1453.

27. McColl KE, El-Omar E, Gillen D. Interactions between H. pylori infection, gastric acid secretion and anti-secretory therapy. Br Med Bull 1998; 54:121-138.

28. Rocha JRM, Ribeiro U, Cecconello I, Sallum RA, Takeda F, Nasi A, et al. Gastric secretory and hormonal patterns in end-stage chagasic achalasia. Dis Esophagus 2009; 22:606-610.
29. Ceneviva R, Módena JLP, Castelfranchi PL. Doença de Chagas e úlcera gástrica. Arq Gastroenterol 1971; 8:85-88.

30. Rocha GA, Rocha AMC, Silva LD, Santos A, Bocewicz ACD, Queiroz RM, et al. Transmission of Helicobacter pylori infection in families of preschool-aged children from Minas Gerais, Brazil. Trop Med Int Health 2003; 8:987-991.

31. Parente JML, Silva BB, Palha-Dias MPS, Zaterka S, Nishimura NF, Zeitune JM. Helicobacter pylori infection in children of low and high socioeconomic status in northeastern Brazil. Am J Trop Med Hyg 2006; 75:509-512.

32. Schreiber S, Bucker R, Groll C, Azevedo-Vethacke M, Garten D, Scheid P, et al. Rapid loss of motility of Helicobacter pylori in the gastric lumen in vivo. Infect Immun 2005; 73:1584-1589.

33. Amieva MR, El-Omar EM. Host-bacterial interactions in Helicobacter pylori infection. Gastroenterol 2008; 134:306-323. 